\title{
DETERMINAÇÃo DE PROTEÍNAS TOTAIS VIA ESPECTROFOMETRIA: VANTAGENS E DESVANTAGENS DOS MÉTODOS EXISTENTES
}

\author{
Dimas A. M. Zaia* \\ Departamento de Química - CCE - Universidade Estadual de Londrina - 86051-970 - Londrina - PR \\ Cássia Thaïs B. V. Zaia \\ Departamento de Ciências Fisiológicas - CCB - Universidade Estadual de Londrina - 86051-970 - Londrina - PR \\ Jaim Lichtig \\ Instituto de Química - Universidade de São Paulo - 05599-970 - São Paulo - SP
}

Recebido em 23/7/97; aceito em 19/6/98

\begin{abstract}
DETERMINATION OF TOTAL PROTEIN BY SPECTROPHOTOMETRY: ADVANTAGES AND DISADVANTAGES OF PROPOSED METHODS. Spectrophotometric determination of total protein is used in several areas such as clinical analysis, food science and technology, biochemistry, protein chemistry, physiology. Five spectrophotometric methods are mostly used: biuret, Lowry, Bradford, Smith and UV absorption. In this review a general overview of these methods is presented (interferences, applications); other methodologies are also discussed.
\end{abstract}

Keywords: protein; spectrophotometry; protein analysis.

\section{INTRODUÇÃO}

O desenvolvimento de metodologias e estudos comparativos de metodologias espectrofotométricas para a determinação de proteínas totais sempre foram de grande interesse para profissionais, tanto ligados à indústria de alimentos, laboratórios de análises clínicas, como para pesquisadores de diversas áreas. Apesar de os profissionais serem de diferentes áreas e, portanto, com objetivos diferentes, observamos que os questionamentos são sempre os mesmos: Quais são os principais interferentes no método que estou usando? Qual é o método mais adequado para meu caso? Qual é o princípio envolvido no método que estou usando?

Esta revisão, portanto, tem por objetivo abordar diversos aspectos dos métodos espectrofotométricos utilizados para a determinação de proteínas totais em diferentes meios.

As proteínas desempenham papéis extremamente importantes, na maioria dos processos biológicos, atuando como enzimas, hormônios, neurotransmissores, transportadores através das membranas celulares e outros ${ }^{1,2}$.

O desenvolvimento de metodologias para determinar proteínas tem, cada vez mais, se tornado de fundamental relevância em várias áreas do conhecimento, como por exemplo, em análises clínicas ${ }^{1}$, favorecendo o diagnóstico de certas doenças correlacionadas com a alteração da quantidade de proteínas nos fluidos biológicos; em nutrição animal ${ }^{3}$, ressaltando o aproveitamento racional de nutrientes; em problemas relacionados à nutrição humana ${ }^{1,4,5}$, como obesidade, anorexia nervosa, desnutrição, devendo as dietas apresentar teor balanceado de proteínas; em tecnologia e ciências de alimentos ${ }^{6}$, objetivando o aproveitamento racional da matéria prima e o melhoramento dos produtos novos e já existentes; em ecologia $^{7}$, relacionando o comportamento alimentar com a quantidade de proteína ingerida dos alimentos, favorecendo o entendimento dos vários aspectos da vida dos animais silvestres; e na área de química de proteínas objetivando purificar novas proteínas e enzimas ${ }^{8}$.

Estas são apenas algumas das mais importantes aplicações analíticas para metodologias de determinação de proteínas totais; obviamente, existem muitas outras de grande relevância.

Os métodos para a determinação da concentração de proteínas totais são muito variados, no entanto, as metodologias mais utilizadas são as espectrofotométricas no ultra-violeta e no visível (UV-Vis).

\section{MÉTODOS ESPECTROFOTOMÉTRICOS MAIS UTILIZADOS PARA A DETERMINAÇÃO DE PROTEÍNAS TOTAIS}

Muitos métodos espectrofotométricos, ao longo dos anos, têm sido propostos para a determinação de proteínas totais, mas não existe uma metodologia considerada de uso universal para todos os meios. Os métodos geralmente mais utilizados são o do biureto", de Lowry ${ }^{10}$, do "Coomassie brilliant blue" BG-250 ou reagente de Bradford ${ }^{11}$, do BCA ou reagente de Smith $^{12}$, e de absorção de proteínas no ultravioleta ${ }^{13}$. A seguir serão discutidas as vantagens e desvantagens destas cinco metodologias.

\section{O MÉTODO DE BIURETO}

\section{Princípio}

As origens do método do biureto podem ser traçadas desde a proposta inicial de Autenrieth, em 1915; posteriormente diversos autores propuseram modificações do mesmo, sendo, atualmente, a proposta metodológica de Gornall e cols ${ }^{9}$. a mais utilizada.

O método se baseia na reação do reativo do biureto, que é constituído de uma mistura de cobre e hidróxido de sódio com um complexante que estabiliza o cobre em solução, sendo o tartarato de sódio o recomendado por Gornall e cols. ${ }^{9}$. O cobre, em meio alcalino, reage com proteínas formando um complexo quadrado planar com a ligação peptídica. O produto de reação apresenta duas bandas de absorção, uma em $270 \mathrm{~nm}$ e outra em $540 \mathrm{~nm}$. Apesar da banda na região de $270 \mathrm{~nm}$ aumentar em seis vezes a sensibilidade do método do biureto ${ }^{14}$, a banda na região de $540 \mathrm{~nm}$ é a mais utilizada para fins analíticos, porque diversas substâncias, normalmente presentes na maioria dos meios analisados, absorvem na região de $270 \mathrm{~nm}$ causando muita interferência no método.

\section{Aplicações}

O método de biureto tem sido aplicado para determinar a 
concentração de proteínas totais em diversos meios, sendo eles: soro ou plasma sangüíneo ${ }^{15,16,18,19}$, líquido cérebro espinhal (líquior) ${ }^{20,21}$, urina ${ }^{22-24}$, alimentos ${ }^{25-29}$, saliva ${ }^{30}$, fibrinogênio $^{31}$ e tecido animal ${ }^{32}$. O método de biureto tem sido, também, utilizado em análise por injeção em fluxo ${ }^{19}$, assim como em alguns métodos cinéticos ${ }^{21,33}$. Apesar de ser rápido, utilizar reagentes de baixo custo e não apresentar grande variação da absortividade específica para diferentes proteínas ${ }^{9,20,21,30}$, este método não é muito sensível, como foi destacado por diversos autores ${ }^{20,24,30}$, colocando-o em grande desvantagem, em relação a outras metodologias, e por isto tem sido, ao longo dos anos, substituído por métodos mais sensíveis. Mesmo assim, o método de biureto continua sendo recomendado para a determinação da concentração de proteínas totais em plasma sangüíneo pela Associação Americana de Análises Clínicas e por diversos autores ${ }^{15,16,34}$, bem como para a determinação de proteínas totais em saliva ${ }^{30}$ e leite $^{29}$, quando comparado com outros métodos.

\section{Interferentes}

Verifica-se que o método de biureto está sujeito à interferência de substâncias que possam reagir com os íons cobre (II). Na tabela 1 estão listados alguns interferentes; os métodos para sua eliminação variam conforme o caso, como discutido nas referências citadas nessa tabela, no entanto, recomendamos a precipitação das proteínas com ácido tricloroacético e posterior solubilização para determinação das mesmas.

\section{O MÉTODO DE LOWRY}

\section{Princípio}

O método que atualmente conhecemos como de Lowry e cols. ${ }^{10}$, para a determinação de proteínas totais, foi originalmente proposto por $\mathrm{Wu}^{35}$, em 1922, sendo esta a metodologia mais utilizada para a determinação de proteínas. O princípio do método baseia-se numa mistura contendo molibdato, tungstato e ácido fosfórico, (reagente Folin-Ciocalteau), que sofre uma redução quando reage com proteínas, na presença do catalisador cobre (II), e produz um composto com absorção máxima em $750 \mathrm{~nm}$.

Chou e Goldstein ${ }^{36}$ e Legler e cols. ${ }^{37}$ estudaram extensivamente o mecanismo de redução do reagente de Folin-Ciocalteau por proteínas, peptídeos ou aminoácidos. Estes autores ${ }^{36,37}$ sugerem que esta redução ocorra diretamente através das cadeias laterais de alguns aminoácidos (tirosina, triptofano, cisteína, asparagina e histidina), que contribuem com quatro elétrons, ou através da retirada de dois elétrons de cada unidade tetrapeptídica dos peptídeos e proteínas, que é facilitada pela formação do quelato entre o cobre (II) e peptídeos/proteínas.

\section{Aplicações}

A principal vantagem do método de Lowry é a sua alta sensibilidade e, por isto, tem sido utilizado para a determinação da concentração de proteínas totais em diversos meios, sendo eles: líqüor ${ }^{20,38}$, plasma sangüíneo ${ }^{34,39,40}$, saliva huma$\mathrm{na}^{30}$, tecido animal ${ }^{32,41-43}$, plantas ${ }^{44-46}$, suco biliar ${ }^{47}$, membranas $^{48-50}$, leite humano ${ }^{28,51}$ e produtos alimentícios ${ }^{52}$. Sargent ${ }^{53}$ propôs uma modificação no método de Lowry que possibilitou o aumento da sensibilidade em cinqüenta vezes. Tal modificação está baseada no fato de que o verde de malaquita reage com o azul de molibdato produzido no método de Lowry e o produto desta reação absorve fortemente em $690 \mathrm{~nm}$ aumentando a sensibilidade do método de Lowry.

Devido ao seu extenso uso, o método de Lowry e cols. ${ }^{10}$ tem sido utilizado em diversos tipos de equipamentos automatizados ${ }^{43,54-57}$.

Em estudos comparativos de métodos, alguns autores recomendam a utilização da metodologia proposta por Lowry e cols ${ }^{10}$ para determinar proteínas totais em líqüor ${ }^{38}$, tecido animal $^{41}$ e tecido vegetal ${ }^{45}$. Os autores ${ }^{38,41,45}$, de maneira geral, recomendam o método de Lowry, pois no estudo comparativo de metodologias o mesmo mostrou-se mais sensível, com melhor exatidão, menor consumo de amostra e, dependendo do caso, menos suscetível a alguns tipos de interferentes.

\section{Interferentes}

Apesar do método de Lowry e cols. ${ }^{10}$ apresentar uma grande sensibilidade para proteínas, o mesmo possui algumas desvantagens, tais como: estar sujeito a muitos interferentes, apresentar longo tempo de análise, possuir absortividade específica altamente variável para diferentes proteínas, e seguir a Lei de Beer-Lambert apenas numa pequena faixa de concentração de proteínas.

Várias modificações no método de Lowry têm sido propostas para resolver os problemas acima citados. Para aumentar a velocidade da reação, Shakir e cols. ${ }^{58}$ recomendam aquecer a amostra, por 3 minutos, a $37^{\circ} \mathrm{C}$, após a adição de sulfato de cobre alcalino, e por mais três minutos, após a adição do

Tabela 1. Algumas substâncias que interferem na determinação de proteínas totais pelo método de biureto 9 .

\begin{tabular}{|c|c|c|}
\hline Interferentes & Comentários & Referências \\
\hline Bilirrubina & Absorve em $540 \mathrm{~nm}$, sério interferente acima de $70 \mathrm{mg} / \mathrm{L}$. & $9,20,21$ \\
\hline Amônio & $\begin{array}{l}\text { Sulfato de amônio usado como precipitante de } \\
\text { proteínas; em meio alcalino amônia complexa cobre. }\end{array}$ & 9 \\
\hline Lipídios & $\begin{array}{l}\text { Provoca turbidez nas amostras, com conseqüente } \\
\text { aumento da absorção das mesmas. }\end{array}$ & 32 \\
\hline Hemoglobina & Aumenta a absorção das amostras. & 9,21 \\
\hline Dextran-40 e 70 & $\begin{array}{l}\text { Causa turbidez nas amostras, em meio alcalino } \\
\text { com tartarato, devido à formação de um complexo insolúvel } \\
\text { entre o dextran e cobre. }\end{array}$ & $16-18$ \\
\hline $\begin{array}{l}\text { Peptídeos e aminoácidos } \\
\text { livres (His, Ser, Thr) }\end{array}$ & $\begin{array}{l}\text { Reagem com cobre, sendo interferentes em métodos } \\
\text { baseados em cinética de reação. }\end{array}$ & 33 \\
\hline Melanina & Provoca falso positivo & 72 \\
\hline Tampão tris- $\mathrm{HCl}$ e glicose & Reage com o cobre presente no reativo de biureto. & 33 \\
\hline Lactose & Provoca falso positivo & 29 \\
\hline Amido & Provoca falso positivo & 26 \\
\hline
\end{tabular}


reagente de Folin-Ciocalteau. Larson e cols. ${ }^{59}$ recomendam a adição de tri-1,4-dimercaptobutanodiol, 3 minutos após a adição do reagente Folin-Ciocalteau, com o objetivo de aumentar a velocidade de reação e eliminar a etapa de 30 minutos de espera. Alam ${ }^{60}$ propõe um rígido controle do $\mathrm{pH}$ para diminuir o tempo de análise, estabilizar o produto formado e uniformizar as absortividades específicas das diferentes proteínas.

Hartree $^{61}$ fez várias modificações no método de Lowry melhorando a faixa de linearidade e uniformizando as absortividades específicas para algumas proteínas; estas modificações ${ }^{61}$ são as mais utilizadas, apesar de tornar o método de Lowry mais trabalhoso no preparo dos reagentes.

Stauffer ${ }^{62}$ recomenda a construção do gráfico de $\log \mathrm{Abs}$ versus log microgramas de proteína e Hess e cols. ${ }^{63}$ recomendam o uso de alta concentração do reagente Folin-Ciocalteau. Tais procedimentos, segundo estes autores, diminuem o tempo de análise, uniformizam as absortividades específicas para algumas proteínas e/ou aumentam a faixa de linearidade do método de Lowry e cols. ${ }^{10}$.

Diversas substâncias interferentes no método de Lowry são citadas na literatura; estas normalmente causam aumento na absorbância do branco, diminuição da absortividade específica ou formação de algum tipo de precipitado. Os interferentes mais comuns estão listados na tabela 2, tendo-se ainda, como fonte de consulta, uma lista preparada por Bensadoun e Weinstein ${ }^{64}$.

Para a eliminação da maioria dos interferentes citados na tabela 2, sugere-se a precipitação das proteínas utilizando-se: ácido tricloroacético e co-precipitantes ${ }^{42,64,65}$, misturas de metanol-clorofórmio-água ${ }^{48}$ ou hexano-isopropanol ${ }^{49}$. Se o interferente for composto de enxofre, como mercaptanas, por exemplo, aconselha-se o uso de iodo acetato ${ }^{66}$ ou a secagem a vácuo da amostra ${ }^{67}$, se for lipídeo ou melanina sugere-se a adição de detergentes ${ }^{41,68,69}$. Verifica-se que a reação de Lowry é fotossensível ${ }^{70}$ recomendando-se exposição uniforme de luz aos tubos.

Apesar de todos os esforços para melhorar o método de Lowry, isto é, diminuir o tempo requerido para a análise, aumentar a faixa de linearidade para a lei de Beer e tornar mais homogênea as absortividades específicas para diferentes proteínas, o mesmo continua moroso e sujeito a inúmeros interferentes e, nos últimos anos, está sendo substituído por outros métodos, tais como, o método de Bradford e o método de Smith ou do BCA.

\section{O MÉTODO DE BRADFORD}

\section{Princípio}

O método de Bradford ${ }^{11}$ é uma técnica para a determinação de proteínas totais que utiliza o corante de "Coomassie brilliant blue" BG-250.

Este método é baseado na interação entre o corante BG-250 e macromoléculas de proteínas que contém aminoácidos de cadeias laterais básicas ou aromáticas. No pH de reação, a interação entre a proteína de alto peso molecular e o corante BG-250 provoca o deslocamento do equilíbrio do corante para a forma aniônica, que absorve fortemente em $595 \mathrm{~nm}^{76}$.

\section{Aplicações}

O método de Bradford ${ }^{11}$, é mais rápido e sensível que o de Lowry e cols. ${ }^{10}$ e tem sido utilizado para a determinação de proteínas totais em diversos meios: plasma ou soro sangüíneo $^{34,39}$, líqüor ${ }^{20,77-81}$, saliva humana ${ }^{30}$, produtos alimentícios $^{82}$, leite humano ${ }^{28,29,83}$, tecidos de plantas ${ }^{44,45}$, suspensões de células ${ }^{84-86}$, avidina e estreptavidina ${ }^{87}$, urina ${ }^{22,24,79,88-90}$ e detergentes ${ }^{91}$.

Alguns autores recomendam o método de Bradford para a determinação de proteínas totais em leite humano ${ }^{83}$, líqüor ${ }^{80}$ e urina $^{24}$. No entanto, com relação à urina, diversos autores destacam dois fatores contra a utilização desta metodologia, sendo um deles a dependência entre o número de diluições da amostra e o resultado da concentração de proteína obtido e, o outro, a presença de proteínas de baixo peso molecular, subestimando a concentração de proteínas totais na urina, principalmente, de pacientes com proteinúria ${ }^{22,88-90,92-96}$.

Tabela 2. Algumas substâncias que interferem na determinação de proteínas totais pelo método de Lowry e cols. ${ }^{10}$.

\begin{tabular}{|c|c|c|}
\hline Interferentes & Comentários & Referências \\
\hline Compostos fenólicos & $\begin{array}{l}\text { Reagem com o reativo de Folin-Ciocalteau resultando } \\
\text { em falso positivo. }\end{array}$ & $10,44,57,73$ \\
\hline Lipídios & Provocam turbidez das amostras. & $10,41,48,49,69,71$ \\
\hline Detergentes & Provocam a formação de precipitado. & $41,48,49,57,61,65$ \\
\hline Ácido úrico & $\begin{array}{l}\text { Reage com o reativo de Folin-Ciocalteau resultando em } \\
\text { falso positivo. }\end{array}$ & 10,73 \\
\hline Guanina e xantina & $\begin{array}{l}\text { Reagem com o reativo de Folin-Ciocalteau resultando } \\
\text { em falso positivo. }\end{array}$ & 10,73 \\
\hline Sulfato de amônio & $\begin{array}{l}\text { Diminui a absortividade devido à alteração do pH da } \\
\text { amostra. }\end{array}$ & 10,57 \\
\hline Melanina & $\begin{array}{l}\text { Reage com o reativo de Folin-Ciocalteau resultando } \\
\text { em falso positivo. }\end{array}$ & 68,72 \\
\hline Bilirrubina & Aumenta a absorção da amostra. & 20 \\
\hline 4-metilumbeliferona & $\begin{array}{l}\text { Reage com o reativo de Folin-Ciocalteau resultando em } \\
\text { falso positivo. }\end{array}$ & 47 \\
\hline Mercaptanas e cisteína & $\begin{array}{l}\text { Reagem com o reativo de Folin-Ciocalteau resultando } \\
\text { em falso positivo. }\end{array}$ & $48,49,66,67,73$ \\
\hline Tampão tris- $\mathrm{HCl}$ & $\begin{array}{l}\text { Reage com o reativo de Folin-Ciocalteau resultando em } \\
\text { falso positivo. }\end{array}$ & 57,73 \\
\hline Açúcares & $\begin{array}{l}\text { Reagem com o reativo de Folin-Ciocalteau resultando } \\
\text { em falso positivo. }\end{array}$ & $57,61,73-75$ \\
\hline RNA & Aumenta a absorção das amostras & 65,73 \\
\hline
\end{tabular}


Algumas metodologias utilizando equipamentos automatizados ${ }^{80,97-101}$ estão tornando este método mais rápido.

\section{Interferentes}

Apesar do método de Bradford ${ }^{11}$ ser mais rápido, sensível e estar sujeito a um número bem menor de interferentes que o método de Lowry e cols. ${ }^{10}$, o mesmo apresenta algumas desvantagens, tais como a variação da absortividade específica para diferentes proteínas, devido à baixa solubilidade ${ }^{75,102}$ ou baixo peso molecular das mesmas ${ }^{22,88-90}$, e fornecimento de resultados nem sempre reprodutíveis devido ao grau de pureza do corante BG-250 que varia conforme a procedência, sendo recomendável a padronização das condições de reação para cada lote de corante adquirido.

Para tentar tornar mais uniforme a absortividade específica de diferentes proteínas, algumas alternativas foram sugeridas: aumentar a concentração do corante ${ }^{103}$; aumentar a solubilização das proteínas que vão reagir com o corante, usando detergentes $^{24,79,84,86,104-106}$, hidróxido de sódio $^{84,107}$ ou fenol ${ }^{108}$; ou aquecer com uréia e 2-mercaptoetanol ${ }^{109}$. Entretanto, no caso de amostras com proteínas de baixo peso molecular, não recomendamos a utilização deste método.

A falta de linearidade na lei de Beer-Lambert ${ }^{11,107,110}$ tem sido, também, observada devido a uma variação do $\mathrm{pH}$ quando da adição da amostra ao reagente BG-250.

Existem poucas substâncias, citadas na literatura, que são interferentes no método de Bradford. Estes interferentes normalmente reagem com as proteínas impedindo a reação com o corante BG-250 ou reagem com o corante causando aumento na absorbância. A tabela 3 mostra os interferentes mais comuns ao método de Bradford ${ }^{11}$. Os métodos de eliminação destes interferentes variam conforme o caso, como discutido nas referências citadas nessa tabela, no entanto, recomendamos a precipitação das proteínas com ácido tricloroacético.

\section{O MÉTODO DE SMITH OU BCA}

\section{Princípio}

O método proposto por Smith e cols. ${ }^{12}$, também conhecido por método do ácido bicinchoninico (BCA 4,4'-dicarboxi-2,2'- biquinolina), se baseia na reação de cobre (II) com proteínas, em meio alcalino, produzindo cobre (I) e formando um complexo com o $\mathrm{BCA}$, que absorve fortemente na região de $560 \mathrm{~nm}$.

No entanto, Legler e cols. ${ }^{37}$, estudando o papel catalisador do cobre, em meio alcalino, na reação entre proteínas e o reativo de Folin-Ciocauteau, detectaram formação de um intermediário de cobre (III) com peptídeos, porém não detectaram cobre (I), como estabelecido por Smith e cols. ${ }^{12}$, devendo, portanto, ser este mecanismo melhor estudado para se estabelecer qual ou quais intermediários de cobre são formados.

\section{Aplicações}

Este método tem a vantagem de ser mais simples no preparo dos reagentes, tão sensível quanto o método de Lowry e cols. ${ }^{10}$ e relativamente rápido, sendo aplicado na determinação da concentração de proteínas totais em saliva ${ }^{30}$, proteínas celulares $^{41,113}$, interferons ${ }^{75}$, leite humano ${ }^{28}$ e determinação de grupos funcionais ${ }^{114}$

O método de Smith e cols. ${ }^{12}$ tem sido recomendado em estudos de comparação de metodologias para a determinação de proteínas totais em leite humano ${ }^{28}$ e células ${ }^{113}$. Esta metodologia também tem sido adaptada para a determinação de proteínas totais utilizando-se equipamentos automatizados ${ }^{115,116}$.

\section{Interferentes}

O método de Smith e cols. ${ }^{12}$ possui algumas desvantagens, como a dependência da temperatura de incubação das amos$\operatorname{tras}^{12,115}$, a variação da absortividade específica para diferentes proteínas $^{30,75,115}$ e a variação da absorbância com o tempo. Recomendamos, portanto, um rígido controle no tempo de leitura das amostras, após a incubação das mesmas.

Os interferentes, em potencial, do método de Smith e cols. ${ }^{12}$ são aquelas substâncias que reagem com os íons cobre (reações de óxido-redução, formação de complexos, precipitação) ou com o reativo de BCA. A tabela 4 mostra os interferentes mais comuns no método de Smith e cols. ${ }^{12}$. Os métodos de eliminação destes interferentes variam conforme o caso, como discutido nas referências citadas nessa tabela; em muitas situações recomendamos a precipitação das proteínas com ácido tricloroacético.

Tabela 3. Algumas substâncias que interferem na determinação de proteínas totais pelo método de Bradford ${ }^{11}$.

\begin{tabular}{|c|c|c|}
\hline Interferentes & Comentários & Referências \\
\hline Tolbutamida & Provoca falso positivo. & 89 \\
\hline Uréia & Fornece resultado falso positivo, acima de $45 \mathrm{~g} / \mathrm{L}$. & $89,107,109$ \\
\hline $\begin{array}{l}\text { Cloreto de sódio e de } \\
\text { potássio }\end{array}$ & Fornecem resultado falso negativo, acima de $1 \mathrm{M}$ & $85,89,107$ \\
\hline $\begin{array}{l}\text { Detergentes (Triton X- } \\
\text { 100, SDS, Tween-20) }\end{array}$ & $\begin{array}{l}\text { A larga banda de absorção em } 650 \mathrm{~nm} \text {, devido a reação } \\
\text { entre o corante e os detergentes, interfere na banda em } \\
595 \mathrm{~nm} \text {, resultando em falso positivo. }\end{array}$ & $11,76,84-86,91,104,107$ \\
\hline Ciclodextrinas & $\begin{array}{l}\text { Formam um complexo de inclusão com o corante BG- } \\
250 \text {, resultando em falso positivo. }\end{array}$ & 74 \\
\hline $\begin{array}{l}\text { Polifenóis e polifenóis } \\
\text { oxidases }\end{array}$ & $\begin{array}{l}\text { Reagem com as proteínas impedindo a formação do } \\
\text { complexo das mesmas com o corante BG- } 250 \text {. }\end{array}$ & $11,44,45,111$ \\
\hline $\begin{array}{c}\text { 2-mercaptoetanol }+ \\
\text { guanadina }\end{array}$ & Diminuem a absorção da amostra. & 11,109 \\
\hline Glicerol & Provoca falso positivo. & $11,85,107$ \\
\hline Lipídios & Causam turbidez na amostra. & 85 \\
\hline Cloropromazina & Provoca falso positivo. & 112 \\
\hline Fluoreto & Diminui a absorção da amostra. & 78 \\
\hline
\end{tabular}


Tabela 4. Algumas substâncias que interferem na determinação de proteínas totais pelo método de Smith e cols. ${ }^{12}$.

\begin{tabular}{clc}
\hline Interferentes & \multicolumn{1}{c}{ Comentários } & Referências \\
\hline Açúcares em geral & Provocam parcial redução do cobre (II) resultando em & $12,74,75,113$, \\
& falso positivo. & 116,117 \\
EDTA & Complexa íons cobre (II). & 12 \\
Lipídios & Reação entre BCA e lipídios resulta em falso positivo & 41,71 \\
Sulfato de amônio & Resulta falso negativo. & 12,117 \\
Mercaptoetanol e & Provocam redução do cobre (II) resultando em falso & 117 \\
dithiothreitol & positivo. & Reação entre BCA e peróxido de hidrogênio resulta em \\
Peróxido de hidrogênio & falso positivo. & 118 \\
Vitamina C e & Provocam redução do cobre (II) resultando em falso & 112 \\
paracetemol & positivo. & 112 \\
Cloropromazina & Provoca turbidez na amostra. & 112 \\
Penicilinas & Provocam falso positivo. &
\end{tabular}

\section{MÉTODO DE ABSORÇÃO NO ULTRA-VIOLETA}

\section{Princípio}

Este método é baseado no fato de que as proteínas mostram absorção na região de $280 \mathrm{~nm}$ e na região abaixo de $220 \mathrm{~nm}$, sendo a primeira devido a diversos aminoácidos (fenilalanina, cisteína, cistina, metionina, triptofano, histidina e tirosina), e a segunda devido à ligação peptídica ${ }^{13}$. No entanto, em $280 \mathrm{~nm}$, em pH neutro, somente os aminoácidos triptofano, tirosina e cistina possuem uma absortividade molar significativamente grande $^{119,120}$.

\section{Aplicações}

$\mathrm{O}$ método tem sido muito utilizado durante os procedimentos de purificação e separação de proteínas $^{13}$ para a quantificação das mesmas. Suas principais vantagens são as de não destruir a amostra e de ser rápido; na literatura raramente são descritas outras aplicações além desta. O principal motivo desta limitação é que, em amostras complexas, diversas substâncias absorvem no ultra-violeta tornando os resultados pouco confiáveis.

\section{Interferentes}

Este método está sujeito a muitos interferentes, sendo que qualquer substância que apresente uma banda de absorção na região de leitura é um interferente em potencial. Este fato fez com que esta metodologia fosse utilizada somente em processos de purificação de proteínas, onde uma avaliação semiquantitativa é suficiente, na maioria dos casos.

Os métodos discutidos acima são os mais utilizados, porém, como estão sujeitos a limitações, a todo o momento continuam aparecendo, na literatura, modificações das metodologias já existentes, além de propostas de novas metodologias, que serão discutidas a seguir.

\section{NOVOS MÉTODOS ESPECTROFOTOMÉTRICOS PARA A DETERMINAÇÃO DE PROTEÍNAS TOTAIS}

Zaia e cols. ${ }^{121-124}$ propuseram uma metodologia básica utilizando p-benzoquinona (PBQ), para a determinação de proteínas em diversos meios. O método se baseia no fato de que o produto de reação entre PBQ e proteínas absorve em $350 \mathrm{~nm}$. Esta metodologia mostrou-se 10 vezes mais sensível que o método de biureto ${ }^{124}$, de menor custo que o de Lowry e cols. ${ }^{123}$, e mais rápida que os métodos de Lowry e Kjedahl ${ }^{122,123}$. Zaia e cols. ${ }^{121}$ propuseram, ainda, uma metodologia inédita que possibilita, em uma única análise, determinar simultaneamente proteínas e aminoácidos, pois o produto de reação $\mathrm{PBQ} /$ proteína absorve em $350 \mathrm{~nm}$ e o produto de reação $\mathrm{PBQ} /$ aminoácidos absorve em $480 \mathrm{~nm}$. Uma outra quinona, o cloranil, foi utilizada por Rahim e Al-Ghabsha ${ }^{125}$, para a determinação de proteínas totais.

Krystal e cols. ${ }^{126,127}$ propuseram uma metodologia que é 100 vezes mais sensível que o método de Bradford ${ }^{11}$. Este método está baseado no fato de que prata amoniacal liga-se a proteínas e o produto de reação absorve fortemente em $420 \mathrm{~nm}$.

Stoscheck ${ }^{128}$ propôs uma metodologia que é 25 vezes mais sensível que o método de Bradford ${ }^{11}$ e 50 vezes mais sensível que o de Lowry ${ }^{10}$. Neste método, o ouro coloidal, na presença de proteínas, desloca o seu máximo de absorção de 535 para $595 \mathrm{~nm}$. Segundo a autora o método está sujeito a poucos interferentes.

Estas metodologias que utilizam ouro coloidal ou prata amoniacal, possuem um inconveniente óbvio que é a utilização de reagentes caros; no entanto, Krystal e cols. ${ }^{126}$ afirmam que o custo de 10 análises em triplicata é menor que dois centavos de dolar.

Soedjak $^{129}$ propôs uma metodologia em que o eritrosin B reage com proteína formado um cromóforo que absorve fortemente em $545 \mathrm{~nm}$. A sensibilidade desta metodologia está entre 2 e $14 \mu \mathrm{g} / \mathrm{mL}$ de proteína, que é a mesma sensibilidade do método proposto por Zaia e cols. ${ }^{121}$.

$\mathrm{O}$ método da ninhidrina ${ }^{130}$ tem sido utilizado para a determinação de proteínas totais ${ }^{30,44,75}$. Nesta metodologia, as proteínas são submetidas à hidrólise ácida, sendo os aminoácidos liberados determinados com ninhidrina. A desvantagem desta metodologia é o tempo gasto na hidrólise ácida, nos métodos comumente utilizados.

\section{CONCLUSÃO}

Diversos fatores devem ser analisados antes da escolha de uma metodologia para a determinação de proteínas totais, porém, um deles é essencial: o conhecimento, o mais preciso possível, da natureza dos constituintes da amostra e de suas concentrações aproximadas. Isto facilitará a identificação dos possíveis interferentes e conseqüentemente ajudará na escolha do método mais apropriado para cada situação.

Outros fatores, também importantes, são a sensibilidade necessária, que é dependente da concentração de proteína na amostra e do volume de amostra disponível; a rapidez e o custo da metodologia; e, não menos importante, o grau de confiabilidade nos resultados obtidos devido aos interferentes no método escolhido. 
Temos observado que muitas vezes a escolha de uma metodologia para a determinação de proteínas totais é feita com base na popularidade de um determinado método e isto acontece em parte devido à falta de trabalhos de comparação de metodologias. Portanto, acreditamos que muitos trabalhos deste tipo devam ainda ser desenvolvidos principalmente nas áreas de análises clínicas, ciências e tecnologia de alimentos.

\section{AGRADECIMENTOS}

Agradecemos a todas as pessoas que, durante estes anos, compartilharam sua experiência analítica, assim como dispenderam parte de seu tempo em discussões dos problemas de análises de proteínas. CTBVZ agradece ao $\mathrm{CNPq}$ pela bolsa de pesquisador.

\section{REFERÊNCIAS}

1. Ganong, W. F.; Review of Medical Physiology; 17 edição, Prentice-Hall Inc.; San Francisco, 1995.

2. Darnell, J.; Lodish, H.; Baltimore, D.; Molecular Cell Biology; Scientific American Books; New York, 1990.

3. McDonald, P.; Edwards, R. A.; Greenhalgh, J. F. D.; Animal Nutrition; Longman Scientific \& Technical; Hong Kong 1987.

4. National Academy of Sciences-National Research Council; Recommended Dietary Allowances; Publ. 0-30902216-9; Washington 1974.

5. King, B. M.; Neurosc. Biobehav. Rev. 1988, 12, 29.

6. Fennema, O. R.; Principles of Food Science; Marcel Dekker Inc.; New York 1976.

7. Robbins, C.; Wildlife Feeding and Nutrition; Academic Press; New York 1983.

8. Heftmann, E.; Chromatography: A laboratory handbook of chromatografic and electrophoretic methods; Van Nostrand Reinhold Company; New York 1975.

9. Gornall, A. G.; Bardawill, C. J.; David, M. M.; J. Biol. Chem. 1949, 177, 751.

10. Lowry, O. H.; Rosebrough, N. J.; Farr, A. L.; Randall, R. J.; J. Biol. Chem. 1951, 193, 265.

11. Bradford, M. M.; Anal. Biochem. 1976, 72, 248.

12. Smith, P. K.; Krohn, R. I.; Hermanson, G. T.; Mallia, A. K.; Gartner, F. H.; Provenzano, M, D.; Fujimoto, E. K.; Goeke, N, M.; Olson, B. J.; Klenk, D. C.; Anal. Biochem. 1985, $150,76$.

13. Stoscheck, C. M.; In Methods in Enzymology; Deutscher, M. P., Ed.; Academic Press Inc.; New York, 1990.

14. Itzhaki, R. F.; Gill, D. M.; Anal. Biochem. 1964, 9, 401.

15. Doumas, B. T.; Bayse, D. B.; Borner, K.; Carter, R. J.; Clin. Chem. 1981, 27, 1651.

16. Flack, C. P.; Woollen, J. W.; Clin. Chem. 1984, 30, 559.

17. Barnes, D. B.; Pierce, G. F.; Lichti, D.; Landt, M.; Koenig, J.; Chan, K. M.; Clin. Chem. 1985, 31, 2018.

18. Sykes, E.; Grzych, C.; Epstein, E.; Kiechle, F. L.; Clin. Chem. 1987, 33, 1073.

19. Shideler, C, E.; Stewart, K. K.; Crump, J.; Wills, M. R.; Savory, J.; Renoe, B. W.; Clin. Chem. 1980, 26, 1454.

20. Hische, E. A. H.; Van der Helm, H. J.; Van Meegen, M. Th.; Blanken, H. I. G.; Clin. Chem. 1982, 28, 1236.

21. Finley, P. R.; Williams, R. J.; Clin. Chem. 1983, 29, 126.

22. Goren, M. P.; Li, J. T. L.; Clin. Chem. 1986, 32, 386.

23. Morozova, N. A.; Baryshnikova, T. A.; Lab. Delo 1991, 40, 23.

24. Macart, M.; Gerbaut, L.; Clin. Chim. Acta 1984, 141, 77.

25. Reichardt, W.; Eckert, B.; Nahrung 1991, 35, 731.

26. Mitsunaga, T.; Ando, H.; Kinki-Daigaku-Nogakubu-Kiyo 1990, $23,63$.

27. Ramachandran, M.; Grover, A.; Banerjee, B. D.; Hussain, Q. Z.; J. Food Sci. Tecnol. 1984, 21, 99.

28. Keller, R. P.; Neville, M. C.; Clin. Chem. 1986, 32, 120.
29. Verheul, F. E. A. M.; Cornelissen, P. J. H. C.; Clin. Chem. 1986, 32, 2003.

30. Jenzano, J. W.; Hogan, S. L.; Noyes, C. M.; Featherstone, G. L.; Lundblad, R. L.; Anal. Biochem. 1986, 159, 370.

31. Tzvetanova, E. M.; Gotzev, R. K.; Clin. Chem. 1988, $34,430$.

32. Beyer, R. E.; Anal. Biochem. 1983, 129, 483.

33. Kanaya, K. I.; Hiromi, K.; Agric. Biol. Chem. 1987, $51,1885$.

34. Hunn, J. B.; Greer, I. E.; J. Fish Biol. 1990, 36, 617.

35. Wu, H.; J. Biol. Chem. 1922, 51, 33.

36. Chou, S. C.; Goldstein, A.; Biochem. J. 1960, 75, 109.

37. Legler, G.; Müller-Platz, C. M.; Mentges-Hettkamp, M.; Pflieger, G.; Jülich, E.; Anal. Biochem. 1985, 150, 278.

38. Vermes, L. M. S.; Ferri, R. G.; Marlet, J. M.; Rev. Inst. Adolfo Lutz 1977, 37, 11.

39. Nishi, H. H.; Kestner, J.; Elin, R. J.; Clin. Chem. 1985, $31,95$.

40. Schlabach, T. D.; Anal. Biochem. 1984, 139, 309.

41. Upreti, G. C.; Ratcliff, R. A.; Riches, P. C.; Anal. Biochem. 1988, 168, 421.

42. Retz, K. C.; Steele, W. J.; Anal. Biochem. 1977, 79, 457.

43. Harrington, C. R.; Anal. Biochem. 1990, 186, 285.

44. Marks, D. L.; Buchsbaum, R.; Swain, T.; Anal. Biochem. 1985, 147, 136.

45. Mattoo, R. L.; Ishaq, M.; Saleemuddin, M.; Anal. Biochem. 1987, 163, 376.

46. Eze, J. M. O.; Dumbroff, E. B.; Can. J. Bot. 1982, 60, 1046.

47. Marinelli, R. A.; Luquita, M. G.; Garay, E. A. R.; Clin. Chem. 1987, 33, 1475.

48. Wessel, D.; Flügge, UI.; Anal. Biochem. 1984, 138, 141.

49. Rodríguez-Vico, F.; Martínez-Cayuela, M.; GarcíaPeregrín, E.; Ramírez, H.; Anal. Biochem. 1989, 183, 275.

50. i, T. H.; Anal. Biochem. 1973, 52, 517.

51. Patton, S.; Huston, G. E.; Nutr. Rep. Int. 1984, 30, 1401.

52. Sebecic, B.; Nahrung . 1987, 31, 817.

53. Sargent, M. G.; Anal. Biochem. 1987, 163, 476.

54. Oosta, G. M.; Mathewson, N. S.; Catravas, G. N.; Anal. Biochem. 1978, 89, 31.

55. Lüdi, H.; Bärtschi, A.; Anal. Chim. Acta 1989, 217, 359.

56. Clifton, P. M.; Chang, L.; Mackinnon, A. M.; Anal. Biochem. 1988, 172, 165.

57. Fryer, H. J. L.; Davis, G. E.; Manthorpe, M.; Varon, S.; Anal. Biochem. 1986, 153, 262.

58. Shakir, F. K.; Audilet, D.; Drake III, A. J.; Shakir, K. M. M.; Anal. Biochem. 1994, 216, 232.

59. Larson, E.; Howlett, B.; Jagendorf, A.; Anal. Biochem. 1986, 155, 243.

60. Alam, A.; Anal. Biochem. 1992, 203, 121.

61. Hartree, E. F.; Anal. Biochem. 1972, 48, 422.

62. Stauffer, C. E.; Anal. Biochem. 1975, 69, 646.

63. Hess, H. H.; Lees M. B.; Derr, J. E.; Anal. Biochem. 1978, 85, 295.

64. Bensadoun, A.; Weinstein, D.; Anal. Biochem. 1976, 70, 241.

65. Polacheck, I.; Cabib, E.; Anal. Biochem. 1981, 117, 311.

66. Ross, E.; Schatz, G.; Anal. Biochem. 1973, 54, 304.

67. Makkar, H. P. S.; Sharma, O. P.; Negi, S. S.; Anal. Biochem. 1980, 104, 124.

68. Vedralová, E.; Borovansky, J.; Duchoñ, J.; J. Biochem. Biophys. Meth. 1987, 14, 343.

69. Kashyap, M. L.; Hynd, B. A.; Robinson, K.; J. Lipid Res. 1980, $21,491$.

70. Dawson, J. M.; Heatlie, P. L.; Anal. Biochem. 1984, 140, 391.

71. Kessler, R. J.; Fanestil, D. D.; Anal. Biochem. 1986, 159, 138.

72. Borovansky, J.; Melezínek, I.; Budesínská, A.; Anal. Biochem. 1986, 159, 249.

73. Higuchi, M.; Yoshida, F.; Agric. Biol. Chem. 1978, 42, 1669. 
74. Xu, P. P.; Troupe, C. M.; Sharma, A.; Microchem. J. 1994, 49, 85.

75. Fountoulakis, M.; Juranville, J. F.; Manneberg, M.; J. Biochem. Biophys. Meth. 1992, 24, 265.

76. Compton, S. J.; Jones, C. G.; Anal. Biochem. 1985 , $151,369$.

77. Macart, M.; Gerbaut, L.; Clin. Chim. Acta 1982, 122, 93.

78. Cheung, C. K.; Chan, K. W.; Chan, A. Y. W.; Clin. Chem. 1990, 36, 2011.

79. Macart, M.; Gerbaut, L.; Clin. Chem. 1988, 34, 998.

80. Huang, C. M.; Clin. Chem. 1988, 34, 980.

81. Stahl, M.; Clin. Chem. 1984, 30, 1878.

82. Richard, J. P.; Paquin, P.; Milchwissenschaft 1990, 45, 92.

83. Bergqvist, Y.; Karlsson, L.; Fohlln, L.; Clin. Chem. 1989, $35,2127$.

84. Gogstad, G. O.; Krutnes, M. B.; Anal. Biochem. 1982, 126,355

85. Pande, S. V.; Murthy, M. S. R.; Anal. Biochem. 1994, $220,424$.

86. Fanger, B. O.; Anal. Biochem. 1987, 162, 11.

87. Sharma, H. K.; Tihon, C.; Anal. Biochem. 1988, 170,135

88. Shiba, K. S.; Kanamori, K.; Harada, T.; Nakao, M.; Nakajima, K.; Kodaira, T.; Nakagawa, H.; Clin. Chem. 1985, $31,1215$.

89. Lott, J. A.; Stephan, V. A.; Pritchard Jr., K. A.; Clin. Chem. 1983, 29, 1946

90. Wimsatt, D. K.; Lott, J. A.; Clin. Chem. 1987, 33, 2100.

91. Rosenthal, K. S.; Koussale, F.; Anal. Chem. 1983, 55, 1115.

92. Goren, M. P.; Wright, R. K.; Li, J. T. L.; Clin. Chem. 1985, 31,1771 .

93. Dilena, B. A.; Penberthy, L. A.; Clin. Chem. 1984, 30, 1589.

94. Heick, H. M. C.; Mohammed, A.; Clin. Chem. 1984, 30,1104 .

95. Shahangian, S.; Brown, P. I.; Ash, K. O.; Clin. Chem. 1983, 29, 1452 .

96. Heick, H. M. C.; Mohammed, A.; Charbonneau, F.; Clin. Chem. 1983, 29, 1863.

97. Gillery, P.; Locre, F.; Malgras, A.; Borel, J. P.; Clin. Chem. 1985, 31, 1092.

98. Korenaga, T.; Zhou, X.; Izawa, M.; Takahashi, T.; Moriwake, T.; Anal. Chimica Acta 1992, 261, 67.

99. Joern, W. A.; Schmoele, L.; Clin. Chem. 1981, 27, 1305.

100. Redinbaugh, M. G.; Campbell, W. H.; Anal. Biochem. 1985, 147, 144.

101. Kanaya, K. I.; Hiromi, K.; Agric. Biol. Chem. 1988, $52,2615$.

102. Marshall, T.; Williams, K. M.; Anal. Biochem. 1992, 204, 107.
103. Read, S. M.; Northcote, D. H.; Anal. Biochem. 1981, $116,53$.

104. Friedenauer, S.; Berlet, H. H.; Anal. Biochem. 1989, $178,263$.

105. Duhamel, R. C.; Meezan, E.; Brendel, K.; J. Biochem. Biophys. Meth. 1981, 5, 67.

106. Löffler, B. M.; Kunze, H.; Anal. Biochem. 1989, 177,100

107. Stoscheck, C. M.; Anal. Biochem. 1990, 184, 111.

108. Marshall, T.; Williams, K. M.; J. Biochem. Biophys. Meth. 1986, 13,145

109. Gotham, S. M.; Fryer, P. J.; Paterson, W. R.; Anal. Biochem. 1988, 173, 353.

110. Splittgerber, A. G.; Sohl, J.; Anal. Biochem. 1989, 179, 198.

111. Godshall, M. A.; J. Food Sci. 1983, 48, 1346.

112. Marshall, T.; Williams, K. M.; Anal. Biochem. 1991, 198, 352.

113. Goldschmidt, R. C.; Kimelberg, H. K.; Anal. Biochem. 1989, 177, 41.

114. Tyllianakis, P. E.; Kakabakos, S. E.; Evangelatos, G. P.; Ithakissios, D. S.; Anal. Biochem. 1994, $219,335$.

115. Davis, L. C.; Radke, G. A.; Anal. Biochem. 1987, 161, 152.

116. Redinbaugh, M. G.; Turley, R. B.; Anal. Biochem. 1986, $153,267$.

117.Brown, R. E.; Jarvis, K. L.; Hyland, K. J.; Anal. Biochem. 1989, $180,136$.

118. Baker, W. L.; Anal. Biochem. 1991, 192, 212.

119. Groves, W. F.; Davis Jr., F. C.; Sells, B. H.; Anal. Biochem. 1968, 22, 195.

120. Pace, C. N., Vajdos, F.; Fee, L.; Grimley, G.; Gray, T.; Protein Sci. 1995, 4, 2411.

121. Zaia, D. A. M.; Barreto, W. J.; Santos, N. J.; Endo, A. S.; Anal. Chim. Acta 1993, 277, 89.

122. Barreto, W. J.; de Aquino, M.; Zaia, D. A. M.; Anal. Letters 1990, 23, 1279.

123. Zaia, D. A. M.; Rockenbach, S. R.; Obara, M. M.; Barreto, W. J.; Arizawa, S.; Curi, R.; Lichtig, J.; Anal. Letters 1992, 25, 1225.

124. Zaia, D. A. M.; Obara, M. M.; Rockenbach, S. R.; Barreto, W. J.; Gaziri, L. C. J.; Zaia, C. T. B.; Lichtig, J.; Braz. J. Med. Biol. Res. 1992, 25, 549

125. Rahim, S. A.; Al-Ghabsha, T. S.; Egypt J. Chem. 1977, 20,627

126. Krystal, G.; Macdonald, C.; Munt, B.; Ashwell, S.; Anal. Biochem. 1985, 148, 451.

127. Krystal, G.; Anal. Biochem. 1987, 167, 86.

128. Stoscheck, C. M.; Anal. Biochem. 1987, 160, 301.

129. Soedjak, H. S.; Anal. Biochem. 1994, 220, 142.

130. Moore, S.; J. Biol. Chem. 1968, 243, 6281. 